\title{
Emphysematous and Granulomatous Submucosal Rumenitis in a Feedlot Nellore Steer
}

\author{
Juliana Ferreira Rocha', Yasmin Daoualibi', Cíntia De Lorenzo'², Ana Paula de Castro Pires', \\ Marilene de Farias Brito' ${ }^{1}$, Vinícius Carneiro de Souza ${ }^{3}$, Pedro Malafaia ${ }^{3}$ \& Daniel Guimarães Ubiali'
}

\begin{abstract}
Background: Emphysematous rumenitis is a condition characterized by gas filled bubbles or cysts in the ruminal mucosa. Although a similar pathology is reported from swine and humans, the incidence of this disease in cattle seems to be scarce. The etiology of emphysematous rumenitis is uncertain once many factors can be involved in its pathogeny, a single cause is difficult to ascertain. This lesion usually fails to display specific clinical signs; however, some degree of malabsorption and weight loss is expected. We described a case of emphysematous granulomatous submucosal rumenitis in a 2.5-yearold feedlot Nellore steer that presented reduction on daily weight gain.

Case: Rumen fragments of a 2.5-year-old Nellore steer were submitted for histopathological evaluation at the Sector of Pathological Anatomy (SAP) of the Rural Federal University of Rio de Janeiro, Brazil. The specimens were part of an experimental trial to evaluate the effect of phosphorus $(\mathrm{P})$ supplementation on nutrient intake, performance and $\mathrm{P}$ balance in fifty feedlot Nellore steers. Following a short adaptation period, in which behavioral observations were made twice daily to assess possible adverse factors, all steers were fed with balanced diet for one hundred and sixteen days. The steers were then slaughtered in order to evaluate macroscopic changes in the gastrointestinal system. Rumen and abomasum of each steer was emptied, washed with tap water and grossly examined. One steer presented ruminal lesion, while the other forty-nine did not show any ruminal injury. Throughout the experiment the affected steer showed reduction of daily weight gain; but during clinical examination no additional clinical sign was seen. At gross inspection, a reduction in the amount of muscular and adipose tissue was seen. Multiple coalescent bullous elevated structures measuring three to ten $\mathrm{mm}$ diameter were covering about $40 \%$ of the ruminal surface. The affected ruminal mucosa showed irregular and atrophic papillae. Rumen samples were processed routinely and stained with Hematoxylin and Eosin, Period Acid Schiff (PAS), Grocott's Methenamine Silver (GMS), Ziehl-Neelsen (ZN), Brown-Hopps (Gram), Giemsa and Toluidine Blue (TB) stains. Additionally formalin-fixed, paraffin wax-embedded sections were stained with a primary polyclonal rabbit antibody for Escherichia coli. Histologically the submucosa was largely replaced by cyst-like enlarged lymphatic vessels filled with gaseous content and the ruminal submucosa was infiltrated by macrophages, multinucleated giant cells, eosinophils, lymphocytes and plasma cells. Special stains were negative for granules within the mast cells, fungi, acid-fast bacilli, bacteria and protozoa. E. coli was immuno-labeled only at the ruminal epithelial surface.

Discussion: This paper provided a description of a rare and possible underdiagnosed condition in cattle to highlight the necessity of recognizing ruminal changes during slaughterhouse inspection. The spontaneous and extensive emphysematous rumenitis described in this paper showed histological similarities with the analogous condition documented in the small and large intestine, mesentery and mesenteric lymph node of swine. The etiology and pathogenesis of emphysematous submucosal rumenitis remain unknown. We believe that the lesion described was the reason for the decrease of weight gain of the steer; therefore it should be considered as a differential diagnosis for conditions that affect weight gain and performance of cattle.
\end{abstract}

Keywords: cattle, veterinary pathology, feedlot, emphysema, rumen.

${ }^{1}$ Veterinary Pathology Sector, Department of Epidemiology and Public Health, Federal Rural University of Rio de Janeiro(UFRRJ), Seropédica, RJ, Brazil. ${ }^{2}$ Veterinary Pathology Sector, Institute of Veterinary Medicine, Federal University of Rio Grande do Sul (UFRGS), Porto Alegre, RS, Brazil ${ }^{3}$ Department of Animal Nutrition and Pastures, Institute of Animal Science, UFRRJ, Seropédica. CORRESPONDENCE: D.G. Ubiali [danielubiali@ hotmail.com - Tel.: + 55 (21) 2682-2805]. Setor de Anatomia Patológica - UFRRJ. BR 465 Km 7. CEP 23890-000 Seropédica, RJ, Brazil. 


\section{INTRODUCTION}

Emphysematous rumenitis is a rare condition characterized by gas filled bubbles or cysts within the ruminal mucosa. A similar lesion is reported in the intestinal submucosa of swine, described as gas filled vesicles associated with granulomatous inflammatory reaction [6]. A related condition commonly referred to as Pneumatosis cystoides intestinalis also occurs in humans [11]. Ohfuji [8] described emphysematous rumenitis in 20 cattle. At slaughter, an emphysematous thickening of the ruminal submucosa was noted. Lymphangiectasis with emphysematous and granulomatous reaction associated with eosinophils infiltrates was the main microscopic change. So far, the underlying causes of this pathology remain unknown. Notably, two main factors are necessary for the development of this condition, production of gas and its infiltration into tissue spaces. However, once many factors could be involved in the pathogeny, it is difficult to establish a single etiology. Although animals suffering from gastrointestinal emphysema usually fail to show clinical signs and the condition is recognized only at slaughter. It is expected that cases of extensive involvement will result in some degree of nutrient malabsorption [6]. In this paper we described a case of emphysematous granulomatous submucosal rumenitis in a feedlot Nellore steer, especially in regard to its etiology and pathogenesis.

\section{CASE}

In February of 2015, rumen fragments of a 2.5-year-old Nellore steer were submitted to histopathological evaluation at the Anatomical Pathology Sector of the Rural Federal University of Rio de Janeiro, Brazil (SAP 32978). The specimen was part of an experimental trial to evaluate the effect of phosphorus (P) supplementation on nutrient intake, performance and $\mathrm{P}$ balance in a feedlot of Nellore steers.

The experiment was conducted as it follows: Fifty Nellore steers with $294 \pm 21 \mathrm{~kg}$ of initial body weight (BW) were allocated in a pasture of Brachiaria brizantha cv. Xaraés for 49 days (June $8^{\text {th }}$ to July $28^{\text {th }}$, 2014). Throughout the adaptation period, behavioral observations were made twice daily to assess possible adverse clinical signs. A detailed clinical examination was conducted when necessary. Cattle had free access to fresh water and sodium chloride throughout the adaptation period.
Prior to the fattening phase (July $20^{\text {th }}$ to August $\left.1^{\text {st }}, 2014\right)$ a total mixed ration (TMR) was offered at $2.2 \%$ of the BW. The TMR contained 60:40 roughage to concentrate ratio on a dry matter (DM) basis. Roughage source was sugarcane bagasse. The concentrate was composed of $600 \mathrm{~g}$ ground corn, $280 \mathrm{~g}$ citrus pulp, $110 \mathrm{~g}$ soybean meal and $10 \mathrm{~g}$ urea per kg. The fattening TMR diet had 20\% sugarcane bagasse and $80 \%$ concentrate (464 g ground corn, $208 \mathrm{~g}$ citrus pulp, 88 $\mathrm{g}$ soybean meal, $32 \mathrm{~g}$ mineral mix and $8 \mathrm{~g}$ urea per $\mathrm{kg}$ $\mathrm{DM}$ ); the fattening TMR diet was offered at $2.1 \%$ of the BW for 116 days.

After 116 days, the steers were slaughtered and the gastrointestinal system evaluated. Rumen and abomasum of each steer were emptied, washed with tap water and grossly examined.

At the time of purchase (June $8^{\text {th }}, 2014$ ), the steer, subject of our study, had a BW of $291 \mathrm{~kg}$, whereas the other steers-averaged $294 \pm 21 \mathrm{~kg}$. At the beginning of the feedlot fattening phase (August $2^{\text {nd }}, 2014$ ) the affected steer weighed $284 \mathrm{~kg}$ and was considered healthy after clinical examination of the whole group. At slaughter on November $26^{\text {th }}, 2014$, the steer weighed $326 \mathrm{~kg}$ and had an average daily gain (ADG) and dry matter intake (DMI) of $0.36 \mathrm{~kg}$ and $3.38 \mathrm{~kg}$ respectively. Whereas the mean body weight of the other steers was $434 \mathrm{~kg}$, and the ADG and DMI were 1.11 $\mathrm{kg}$ and $7.97 \mathrm{~kg}$, respectively.

Gross inspection of the steer revealed decrease in the amount of muscular and adipose tissue. An extensive lesion covering approximately $40 \%$ of the ruminal surface was noted. Grossly, it consisted of

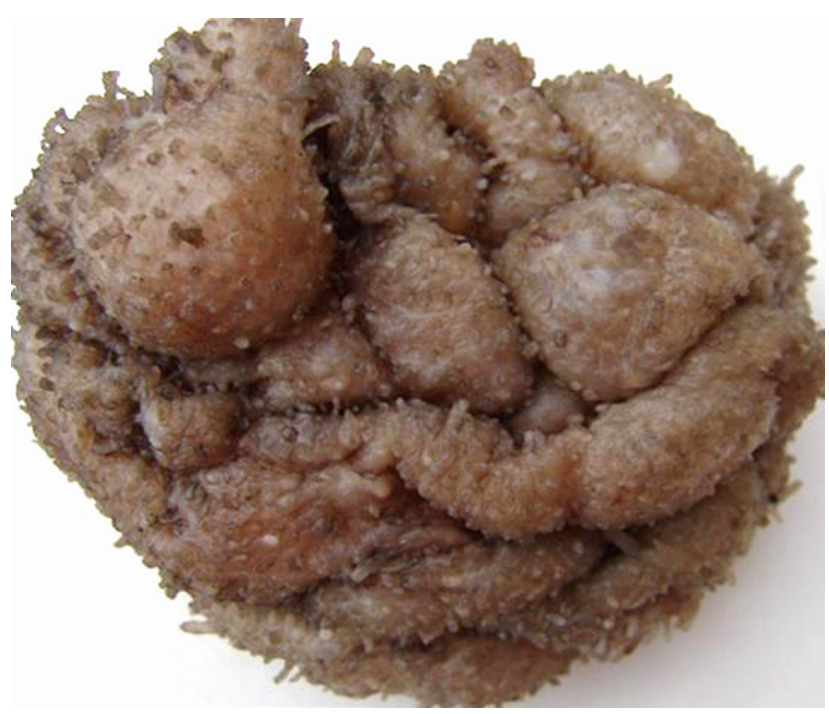

Figure 1. Rumen fragment with wall thickening, cystic areas and a reduction size and number of rumen papillae. 


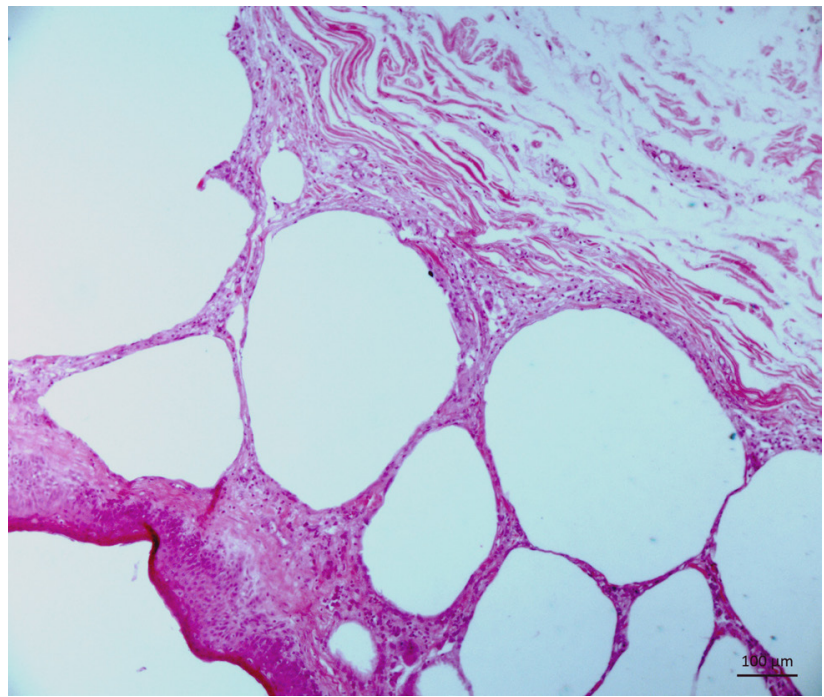

Figure 2. Rumen with enlarged lymphatic vessels in the submucosa enclosed by thin walls [HE. Obj. 20x].

multiple coalescent bullous elevated structures of 3 to $10 \mathrm{~mm}$ diameter (Figure 1). These apparent gas bubbles had a thin wall and a cross section into the membrane revealed a colorless, odorless gas and a small amount of clear liquid. The affected ruminal mucosa showed irregular and atrophic papillae, while other areas were completely free of these structures. Some ruminal areas without gas bullous had hyperemia. The 49 reminiscent steers of the experiment had not ruminal lesions.

Ruminal fragments, submitted for histological examination, were processed routinely and stained with Hematoxylin-Eosin, Period Acid Schiff (PAS), Grocott's Methenamine Silver (GMS), Ziehl-Neelsen (ZN), Brown-Hopps (Gram), Giemsa and Toluidine Blue (TB) stains.

Formalin-fixed, paraffin wax-embedded sections were stained with a commercial primary polyclonal rabbit antibody for Escherichia coli 1001 $\left[\operatorname{Virostart}^{\circledR}\right]^{1}$ (1:200). Antigen retrieval was performed with citrate buffer ( $\mathrm{pH}$ 6.0) in a microwave oven. After overnight incubation at room temperature, a secondary biotinylated antibody (Kit-LSAB-HPR $\left.{ }^{\circledR}\right)^{2}$ was applied. Substrate development occurred with the addition of 3-amino-9-etilcarbazol. The sections were counterstained lightly with hematoxylin and coverslipped. Sections were considered positive when structures consistent with the morphology of bacteria were immunolabelled. Samples of tissue from swine colibacillosis, previously confirmed as positive by culture for colibacillosis, were used as a positive control.

Histologically the submucosa and occasionally the lamina propria was largely replaced by cyst-like en-

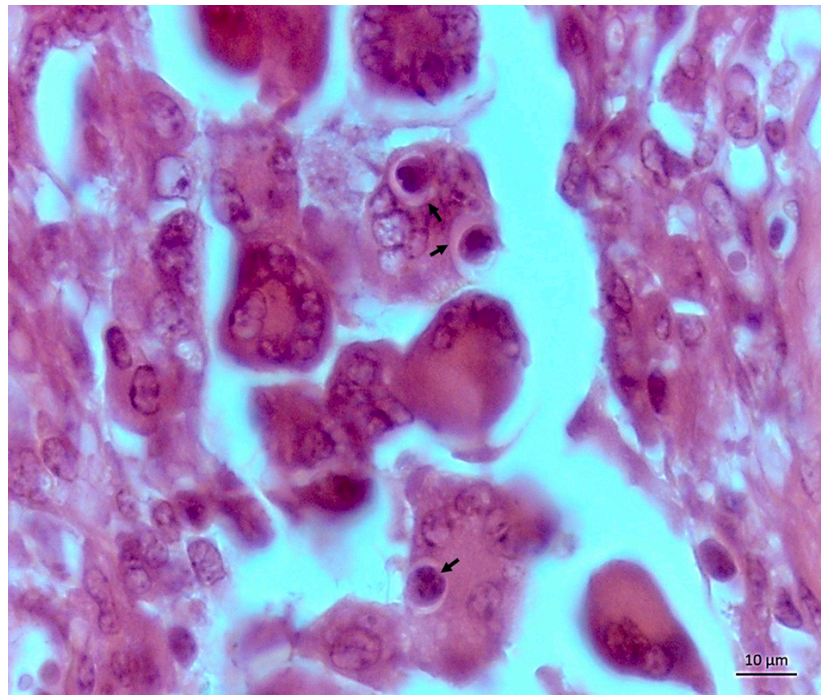

Figure 3. Eosinophils phagocytosed by multinucleated giant cells [HE. Obj. 100x].

larged lymphatic vessels filled with a gaseous content (Figure 2). The ruminal submucosa was infiltrated by macrophages, multinucleated giant cells, eosinophils, lymphocytes and plasma cells. Dilated lymphatic vessels were lined by a single layer of endothelial cells and eventually contained small amount of serous and amphophilic fluid. Eosinophils phagocytosed and vacuoles containing cell debris were seen in macrophages or multinucleated giant cells (Figure 3). The microscopic evaluation failed to reveal any viral inclusions and parasitic infections. TB, PAS, GMS, ZN, and Giemsa stains were negative for granules within the mast cells, fungi, acid-fast bacilli and protozoa respectively. Gram stain failed to show any bacteria in the submucosa and within macrophages and multinucleated giant cells. E. coli was immuno-labeled at the ruminal epithelial surface and it was negative in the submucosa, macrophages and multinucleated giant cells.

\section{DISCUSSION}

Diagnosis of emphysematous and granulomatous submucosal rumenitis was supported by clinical and pathological findings. The spontaneous and extensive emphysematous rumenitis, described in this paper, showed histological similarities with the analogous condition documented in the small and large intestine, mesentery and mesenteric lymph node of swine. Gas production by bacteria, notably in swine consuming large amounts of non-structural carbohydrate, has been suggested as a possible cause; however, the exact etiology still needs to be established $[3,14]$. 
E. coli infection was discarded as a differential diagnosis due to the lack of histopathological and histochemistry changes compatible with the disease. In swine, E. coli infection is characterized by diarrhea, dehydration and emphysematous lymphangitis [6,7], which differ from our field and laboratory findings.

In Japan, twenty slaughtered cattle had ruminal lesions defined as an emphysematous lymphangitis in the submucosa associated with macrophages, multinucleated giant cells and eosinophils infiltration, without evidence of microbial involvement [8]. Those changes were similar to the lesions seen in the present case. The author proposed an immune-mediated mechanism based on increase vascular permeability as a consequence of mastocytic, eosinophilic, lymphopasmacytic and granulomatous inflammation associated with edema and fibrinous exudation. In order to explain the immuno-mediated mechanism, immunolabeling of eosinophil phagocytosis events by macrophages and giant cells with specific assay (TUNEL) was performed. A TUNEL positive result seems to represent a mechanism of late-phase of allergic inflammatory response, as described in atopic human subjects [17]. Ingestion of apoptotic eosinophils by alveolar macrophages and bronchial epithelial cells may also indicate resolution of inflammation in human asthmatic patients [16]. Histological changes in our study were unfitting with acute hypersensitivity reaction; however, the ruminal histology revealed phagocytosis of eosinophils by macrophages or giant cells, which could indicate a late-phase response of a hypersensitivity reaction.

Rumen neutrophilic epithelial pustules were found in $60 \%(12 / 20)$ of the samples suggesting an acute rumen acidosis [8]. In spite of same similar ruminal morphology, no signs of rumen acidosis or pustules were seen in our study.

A known condition capable of induce ruminal emphysema in calves was described after ingestion of elevated quantities of non-structural carbohydrates (e.g. starch, lactose and glucose). Fermenting bacterial microbiota is believed to be the source of the excessive gas and volatile fatty acids [10]. Additional bacteria including Sarcina spp. and Clostridium spp. have been reported to produce abomasal emphysema in calves and lambs; the lesions in those conditions included edema, hyperemia, hemorrhage, and epithelial necrosis [2,5,12,15].

Once the steer was kept under the same nutritional and managing conditions as the remaining 49 unaffected steers, we hypothesize the lesion found in the rumen of that steer occurred most likely due to individual circumstances unrelated to the diet or feeding regime.

A Japanese researcher [9] reported two cases of focal emphysematous reticulitis in cattle, which are distinct of the extensive ruminal lesion presented in this paper. His findings were unassociated with any decrease of weight gain or muscular and adipose tissue decrease during gross inspection at slaughter.

Even though the affected feedlot steer had consumed about $0.9 \mathrm{~kg} /$ day (over 12 days of adaptation period) and $1.14 \mathrm{~kg} /$ day during the fattening phase (116 days) of citrus pulp. The granulomatous ruminal lesion described herein, differed from other granulomatous lesions reported in Brazil for citrus pulp poisoning of cattle [13] or by Vicia spp. [1]. Those types of poisoning can affect any organ, but lesions are most prevalent in skin, lymph nodes, adrenal glands, spleen, liver, brain, kidneys and heart. Essentially, the granulomatous and emphysematous lesion in the affected steer were limited to the rumen.

Many conditions can lead to emphysematous lesions in a range of species, specifically involving lymphatic vessels in association with the presence of granulomatous and eosinophilic infiltrates. Similar lesions as reported in this case have been described in the intestine of dogs, rabbits, mice and poultry, in lungs of cattle and in lymph nodes of horses and cattle [9]. Human beings can develop Pneumatosis cystoides intestinalis as a rare, idiopathic or secondary to various disorders, condition characterized by multiple gas-filled cysts in the wall of gastrointestinal tract [4].

This paper provided a description of a scarce and possibly underdiagnosed condition in cattle to highlight the necessity of recognizing ruminal changes during slaughterhouse inspections. Etiology and pathogenesis of emphysematous submucosal rumenitis remain obscure; hence, further investigation is essential to better understanding this disease, especially in regard microbial fermentation, decreases forestomach motility, abnormal feces, causes of inappetence, poor weight gain in feedlot cattle and the feeding with specific or unusual feedsttufs. We believe the lesion described was the reason for the decrease in the weight gain of the steer; therefore, it should be considered as a differential diagnosis to conditions that affect grow, weight gain and performance of cattle.

\section{MANUFACTURERS}

${ }^{1}$ ViroStart. Westbrook, CT, USA.

${ }^{2}$ BioVision Inc. Milpitas, CA, USA.

Declaration of interest. The authors report no conflicts of interest. The authors alone are responsible for the content and writing of the paper. 
J.F. Rocha, Y. Daoualibi, C. Lorenzo, et al. 2018. Emphysematous and Granulomatous Submucosal Rumenitis in a

\section{REFERENCES}

1 Barros C.S.L., Fighera R.A., Rozza D.B., Rech R.R., Sallis S.V. \& Langohr I.M. 2001. Doença granulomatosa sistêmica em bovinos no Rio Grande do Sul associada ao pastoreio de ervilhaca (Vicia spp). Pesquisa Veterinária Brasileira. 21(4): 162-171.

2 Edwards G.T., Woodger N.G.A., Barlow A.M., Bell S.J., Harwood D.G., Otter A. \& Wight A.R. 2008. Sarcina-like bacteria associated with bloat in young lambs and calves. Veterinary Record. 163(13): 391-393.

3 Egerton J.R. \& Murrell T.G.C. 1965. Intestinal Emphysema in pigs in the Western Highlands of New Guinea. Journal of Comparative Pathology. 75(1): 35-39.

4 Itazaki Y., Tsujimoto H., Ito N., Horiguchi H., Nomura S., Kanematsu K., Hiraki S., Aosasa S., Yamamoto J. \& Hase K. 2016. Pneumatosis intestinalis with obstructing intussusception: A case report and literature review. World Journal of Gastrointestinal Surgery. 8(2): 173-178.

5 Leite Filho R.V., Bianchi M.V., Fredo G., Oliveira E.C., Laisse C.J.M., Driemeier D. \& Pavarini S.P. 2016. Abomasite enfisematosa por bactérias do gênero Sarcina em um cordeiro no sul do Brasil. Ciência Rural. 46(2): 300-303.

6 Meyer R.C. \& Simon J. 1977. Intestinal Emphysema (Pneumatosis cystoides intestinalis) in a gnotobiotic Pig. Canadian Journal of Comparative Medicine. 41(3): 302-305.

7 Nieberle K. \& Cohrs P. 1966. Digestive organs. In: Nieberle K. \& Cohrs P. (Eds). Textbook of the Special Pathological Anatomy of Domestic Animals. Oxford: Pergamon Press, pp.289-566.

8 Ohfuji S. 2015. Emphysematous Eosinophilic Lymphangitis in the Ruminal Submucosa of Cattle. Veterinary pathology. 52(6): 1163-1166.

9 Ohfuji S. 2016. Pathology of emphysematous reticulitis in cattle: report of two cases and comparative overview of similar or identical conditions. Comparative Clinical Pathology. 25(4): 805-813.

10 Panciera R.J., Boileau M.J. \& Step D.L. 2007. Tympany, acidosis, and mural emphysema of the stomach in calves: report of cases and experimental induction. Journal of Veterinary Diagnostic Investigation. 19(4): 392-395.

11 Salles V.J.A., Saba E., Cauduro A.B. \& Salgado F.C. 2008. Pneumatose cística intestinal. Revista Brasileira de Coloproctologia. 28(2): 238-240.

12 Songer J.G. \& Miskimins D.W. 2005. Clostridial abomasitis in calves: Case report and review of the literature. Anaerobe. 11(5): 290-294.

13 Tokarnia C.H., Peixoto P.V. \& Cunha B.R.M. 2001. Experimentos com a polpa cítrica em ovinos e coelhos. Pesquisa Veterinária Brasileira. 21(4): 172-176.

14 Uzal F.A., Plattner B.L. \& Hostetter J.M. 2016. Alimentary System. In: Maxie M.G. (Ed). Jubb, Kennedy and Palmer's Pathology of Domestic Animals. 6th edn. Guelph: Elsevier, 87p.

15 Vatn S., Tranulis M.A. \& Hofshagen M. 2000. Sarcina-like bacteria, Clostridium fallax and Clostridium sordelli in lambs with abomasal bloat, haemorrage and ulcers. Journal of Comparative Pathology. 122(2): 193-200.

16 Walsh G.M., Sexton D.W. \& Blaylock M.G. 2003. Corticosteroids, eosinophils and bronchial epithelial cells: new insights into the resolution of inflammation in asthma. Journal of Endocrinology. 178(1): 37-43.

17 Ying S., Meng Q., Taborda-Barata L. \& Kay A.B. 1997. Association of apoptosis of neutrophils and eosinophils and their ingestion by macrophages with resolution of the allergen-induced cutaneous late-phase response in atopic human subjects. Proceedings of the Association of American Physicians. 109(1): 42-50. 